\title{
Experimental Studies on Behaviors of Lanthanides in Interaction between Water and Basaltic Rock Grains \\ Bearings of Tetrad Effect on Conditions
}

\author{
By Masayo Minami,*) Naoko Matsuda, ${ }^{* *)}$ and Akimasa MASudA ${ }^{*)}$ \\ (Communicated by Kazuo Yamasaki, M. J. A., Jan. 12, 1995)
}

\begin{abstract}
The behavior of rare earth elements (REE) in interaction between water and basalt was investigated on different conditions. The W-type tetrad effect was observed for water under gentle environment at room temperature. The REE pattern, having tetrad effect and negative Ce anomaly, is similar to that of seawater. On the other hand, the REE patterns of waters resulting from violent environment, i.e., at high temperature $\left(70^{\circ} \mathrm{C}\right)$ or under operation of supersonic waves, show smooth curve with little if any tetrad effect, rather resembling that of source basalt. It is noted that the tetrad effect often observed in natural waters also appears in simple interaction in situ between pure distilled water and basalt. This results would throw light on understanding of tetrad effects observed in natural waters.
\end{abstract}

Key words : Lanthanide; tetrad effect; natural water; basalt; negative Ce anomaly.

The rare earth elements (REE) have very similar chemical properties. But their ionic radius shows gradual change with increase of atomic number, which controls their distribution in the geological environment. Masuda and Ikeuchi $^{1)}$ recognized a zig-zag feature in the heavy REE pattern of seawater, and interpreted it as a reflection of partially cut-off lanthanide tetrad effect. The tetrad effect is considered to be associated with the $4 \mathrm{f}$ electron filling. ${ }^{2)}$ REE have the increased stability at quarter, half, three-quarter, and complete filled $4 \mathrm{f}$ shells, giving rise to the tetrad effect. The tetrad effect is a welldocumented chemical behavior, as seen in liquid-liquid distribution coefficients. ${ }^{3,4)}$ When distribution coefficients or stability constants (log K) are plotted against atomic number, there are four distinct smooth curves: La-Ce-Pr-Nd, (Pm)-Sm-Eu-Gd, Gd-Tb-DyHo, and Er-Tm-Yb-Lu. In geochemical samples, the tetrad effect is most apparent in natural waters and other fluids, and in rocks having interacted with aqueous solutions. Masuda et $a l .{ }^{5)}$ pointed out that seawater and material precipitated directly from

*) Department of Chemistry, The University of ElectroCommunications, Chofu, Tokyo 182, Japan.

**) Department of Chemistry, The University of Tokyo, Hongo, Tokyo 113, Japan. seawater would possess W-type tetrad effects, while rocks having interacted with water would possess M-type tetrad effects.

Masuda et $a l .{ }^{6)}$ recently proposed a mathematical way ("TRIMY" method) to estimate a degree of tetrad effect in REE pattern void of monoisotopic data. In this approximation method, a quadratic formula $y$ $=a x^{2}+b x+c$ is applied to the observed points, and the value (A) corresponding to the quadratic coefficient $a$ multiplied by 100 is used as a numerical index to indicate the relative magnitude of the tetrad effect. In order to denote the first, second, third and fourth tetrad effects, A is suffixed by subscripts 1, 2, 3 or 4 . However, since $A_{1}$ is assumed to be identical with $A_{2}$ for experimental and mathematical reasons, both $A_{1}$ and $A_{2}$ have been symbolized by $A_{L}$. In this paper, however, the numerical symbols, $\mathrm{A}_{\mathrm{L}}, \mathrm{A}_{3}$ and $\mathrm{A}_{4}$ are replaced by $\mathrm{T}(1,2), \mathrm{T}(3)$ and $\mathrm{T}(4)$. There is no difference in physical meaning between these two systems of symbols.

Primary source of REE in waters is basically attributed to rocks contacted with the waters. Interaction of water and rock would be a key to shapes of REE patterns for natural waters. In this paper, the behavior of REE in interaction between water and rock surface is studied in order to understand the 
Table I. Major elements composition (\%) of the Fuji basalt (after Table IV ${ }^{10)}$ )

\begin{tabular}{cccccccccccccc}
\hline $\mathrm{SiO}_{2}$ & $\mathrm{Al}_{2} \mathrm{O}_{3}$ & $\mathrm{Fe}_{2} \mathrm{O}_{3}$ & $\mathrm{FeO}$ & $\mathrm{MgO}$ & $\mathrm{CaO}$ & $\mathrm{Na}_{2} \mathrm{O}$ & $\mathrm{K}_{2} \mathrm{O}$ & $\mathrm{TiO}_{2}$ & $\mathrm{P}_{2} \mathrm{O}_{5}$ & $\mathrm{MnO}$ & $\mathrm{H}_{2} \mathrm{O}(+)$ & $\mathrm{H}_{2} \mathrm{O}(-)$ & Total \\
\hline 51.09 & 17.62 & 2.64 & 8.42 & 5.09 & 9.68 & 2.80 & 0.76 & 1.38 & 0.26 & 0.21 & 0.28 & 0.06 & 100.29 \\
\hline
\end{tabular}

Table II. Experimental conditions for interaction between water and the basalt

\begin{tabular}{lccl}
\hline Sample & Period & Temperature & \\
\hline B2w & 2 weeks & $20^{\circ} \mathrm{C}$ & \\
B2wHT & 2 weeks & $70^{\circ} \mathrm{C}$ & \\
$\mathrm{B}^{2} \mathrm{wCO}_{2}$ & 2 weeks & $20^{\circ} \mathrm{C}$ & introducing $\mathrm{CO}_{2}$ \\
BUSW & 4 hours & $20^{\circ} \mathrm{C}$ & under supersonic vibration \\
\hline B1L $^{*)}$ & 1 month & $20^{\circ} \mathrm{C}$ & \\
B1S*) $^{*}$ & 1 month & $20^{\circ} \mathrm{C}$ & grain size 200 mesh-1 mm**) \\
\hline
\end{tabular}

*) These data are taken from Masuda et al. (1994).

**) The grain size of the basaltic rock for all samples except for B1S is $1 \mathrm{~mm}-4 \mathrm{~mm}$.

tetrad effect in REE patterns of natural waters.

Sample and analytical methods. The rock used for the present study is a basalt from the Mishima lava at the foot of Mt. Fuji. One of representative previous analyses is given in Table I. The sample was crushed into grains with size of $1 \mathrm{~mm}-4 \mathrm{~mm}$, and soaked in triply distilled water (rock/water weight ratio $=0.11$ ). Four conditions for interaction between water and basaltic rock grains were set up as shown in Table II. The introduction of $\mathrm{CO}_{2}$ into sample system $\mathrm{B}_{2} \mathrm{wCO}_{2}$ was done with caution not to stir up the grains.

Each of samples was filtered by means of a 0.45 $\mu \mathrm{m}$ Millipore filter and separated into rock particulates and water solutions. Each water (1-1.5 liter) was acidified to about $\mathrm{pH}=2$ with distilled $6 \mathrm{~N}$ hydrochloric acid. After addition of a REE spike solution, purified $\mathrm{FeCl}_{3}$ solution was added, then purified $\mathrm{NH}_{4} \mathrm{OH}$ was added to co-precipitate $\mathrm{REE}$ with $\mathrm{Fe}(\mathrm{OH})_{3}$. After the hydroxides were centrifuged, they were dissolved by a little amount of $0.5 \mathrm{~N}$ hydrochloric acid. REE fraction was separated by a cation exchange column (AG $50 \mathrm{~W}-\mathrm{X} 8$ ). The REE abundances were determined by the isotope dilution method using JEOL JMS-05RB mass spectrometer. This method potentially provides the most reliable precise REE data, except monoisotopic elements ( $\mathrm{Pr}, \mathrm{Tb}, \mathrm{Ho}$ and $\mathrm{Tm}$ ). The precision of analyses is better than $3 \%$.

Results and discussion. The results obtained are given in Table III. The data on Leedey chondrite and the basalt used are also listed in Table III. The parenthesized values in the second rows are the values evaluated by normalization with Leedey chondrite, ${ }^{7)}$ and those in the third rows are the basalt-normalized values. REE abundances are usually normalized against another set of REE abundances to eliminate the Oddo-Harkins effect. The most common normalizing reference material is chondritic meteorites, potentially representing the bulk earth. In this study, to clarify the distribution of REE between water (aqueous phase) and basalt (solid phase), the basaltnormalized REE pattern is preferred. The Leedey chondrite-normalized REE patterns for basalt and waters contacted with the basalt are shown in Figs. 1 and 2. The basalt-normalized REE pattern for the waters experimentally obtained are shown in Fig. 3. Since the basalt used for the experiment happens to have rather flat pattern in comparison with the chondrite, the basalt-normalized REE pattern appears to be similar to the chondrite-normalized one. Degrees of the first (second, which is assumed to be identical with first $^{6)}$ ), third and fourth tetrad effects, and Ce anomalies are listed in Table IV, together with the results (B1L and B1S) previously reported. ${ }^{6}$ Here, the estimating procedure for a degree of tetrad effect is identical to that of Masuda et al., ${ }^{6)}$ and a degree of Ce anomaly is defined by $\mathrm{Ce}_{\mathrm{N}} / \mathrm{Ce}_{\mathrm{N}}{ }^{*}$, where $\mathrm{Ce}_{\mathrm{N}}{ }^{*}$ is given by $\left(\left(\mathrm{La}_{\mathrm{N}}\right)^{2} \times \mathrm{Nd}_{\mathrm{N}}\right)^{1 / 3}$. Similarly, a degree of $\mathrm{Eu}$ anomaly is defined by $\mathrm{Eu}_{\mathrm{N}} / \mathrm{Eu}_{\mathrm{N}}{ }^{*}$, where $\mathrm{Eu}_{\mathrm{N}}{ }^{*}$ is given by $\left(\mathrm{Sm}_{\mathrm{N}} \times \mathrm{Gd}_{\mathrm{N}}\right)^{1 / 2}: \mathrm{La}_{\mathrm{N}}, \mathrm{Ce}_{\mathrm{N}}, \mathrm{Nd}_{\mathrm{N}}, \mathrm{Sm}_{\mathrm{N}}, \mathrm{Eu}_{\mathrm{N}}$ and $\mathrm{Gd}_{\mathrm{N}}$ are chondrite- or basalt-normalized values for $\mathrm{La}$, 
Table III. REE abundances $\left(\times 10^{-6} \mathrm{ppm}\right)$ in water contacted with the basalt as well as the data (ppm) on Leedey chondrite and the basalt used

\begin{tabular}{|c|c|c|c|c|c|c|c|c|c|c|}
\hline Sample & $\mathrm{La}$ & $\mathrm{Ce}$ & $\mathrm{Nd}$ & $\mathrm{Sm}$ & $\mathrm{Eu}$ & $\mathrm{Gd}$ & Dy & Er & $\mathrm{Yb}$ & $\mathrm{Lu}$ \\
\hline $\mathrm{B}^{*}$ & $\begin{array}{c}2.80 \\
(7.41)\end{array}$ & $\begin{array}{c}5.98 \\
(6.13)\end{array}$ & $\begin{array}{c}5.51 \\
(7.70)\end{array}$ & $\begin{array}{c}1.26 \\
(5.48)\end{array}$ & $\begin{array}{l}0.399 \\
(4.61)\end{array}$ & $\begin{array}{c}1.42 \\
(4.57)\end{array}$ & $\begin{array}{c}1.46 \\
(3.74)\end{array}$ & $\begin{array}{c}1.28 \\
(5.02)\end{array}$ & $\begin{array}{c}1.36 \\
(5.46)\end{array}$ & $\begin{array}{l}0.252 \\
(6.51)\end{array}$ \\
\hline$* *)$ & $(0.359)$ & $(0.291)$ & $(0.353)$ & $(0.230)$ & $(0.293)$ & $(0.295)$ & $(0.305)$ & $(0.462)$ & $(0.511)$ & $(0.650)$ \\
\hline $\mathrm{B} 2 \mathrm{wHT}$ & $\begin{array}{c}25.0 \\
(66.1) \\
(3.21)\end{array}$ & $\begin{array}{c}65.6 \\
(67.2) \\
(3.20)\end{array}$ & $\begin{array}{c}48.3 \\
(67.5) \\
(3.09)\end{array}$ & $\begin{array}{c}11.4 \\
(49.6) \\
(2.63)\end{array}$ & $\begin{array}{c}3.80 \\
(43.9) \\
(2.79)\end{array}$ & $\begin{array}{c}10.3 \\
(33.1) \\
(2.14)\end{array}$ & $\begin{array}{c}9.97 \\
(25.6) \\
(2.09)\end{array}$ & $\begin{array}{c}6.55 \\
(25.7) \\
(2.37)\end{array}$ & $\begin{array}{c}6.30 \\
(25.3) \\
(2.37)\end{array}$ & $\begin{array}{c}1.03 \\
(26.6) \\
(2.65)\end{array}$ \\
\hline $\mathrm{B} 2 \mathrm{wCO}{ }_{2}$ & $\begin{array}{c}418 \\
(1110) \\
(53.6)\end{array}$ & $\begin{array}{c}832 \\
(852) \\
(40.5)\end{array}$ & $\begin{array}{c}540 \\
(754) \\
(34.6)\end{array}$ & $\begin{array}{c}120 \\
(522) \\
(27.7)\end{array}$ & $\begin{array}{c}28.8 \\
(333) \\
(21.2)\end{array}$ & $\begin{array}{c}154 \\
(495) \\
(32.0)\end{array}$ & $\begin{array}{c}143 \\
(367) \\
(29.9)\end{array}$ & $\begin{array}{c}98.8 \\
(387) \\
(35.7)\end{array}$ & $\begin{array}{c}72.6 \\
(292) \\
(27.3)\end{array}$ & $\begin{array}{c}11.0 \\
(284) \\
(28.4)\end{array}$ \\
\hline BUSW & $\begin{array}{c}6.31 \\
(16.7) \\
(0.809)\end{array}$ & $\begin{array}{c}16.2 \\
(16.6) \\
(0.790)\end{array}$ & $\begin{array}{c}9.46 \\
(13.2) \\
(0.606)\end{array}$ & $\begin{array}{c}2.49 \\
(10.8) \\
(0.574)\end{array}$ & $\begin{array}{c}0.710 \\
(8.20) \\
(0.522)\end{array}$ & $\begin{array}{c}2.78 \\
(8.94) \\
(0.578)\end{array}$ & $\begin{array}{c}2.38 \\
(6.10) \\
(0.498)\end{array}$ & $\begin{array}{c}1.60 \\
(6.27) \\
(0.578)\end{array}$ & $\begin{array}{c}1.48 \\
(5.94) \\
(0.556)\end{array}$ & $\begin{array}{c}0.213 \\
(5.50) \\
(0.549)\end{array}$ \\
\hline $\mathrm{B} 1 \mathrm{~L}$ & $\begin{array}{c}2.75 \\
(7.28) \\
(0.353)\end{array}$ & $\begin{array}{c}5.16 \\
(5.29) \\
(0.252)\end{array}$ & $\begin{array}{c}4.97 \\
(6.94) \\
(0.319)\end{array}$ & $\begin{array}{c}1.16 \\
(5.04) \\
(0.268)\end{array}$ & $\begin{array}{c}0.281 \\
(3.24) \\
(0.207)\end{array}$ & $\begin{array}{c}1.40 \\
(4.50) \\
(0.291)\end{array}$ & $\begin{array}{c}1.37 \\
(3.51) \\
(0.287)\end{array}$ & $\begin{array}{c}1.30 \\
(5.10) \\
(0.469)\end{array}$ & $\begin{array}{c}1.45 \\
(5.82) \\
(0.545)\end{array}$ & $\begin{array}{c}0.275 \\
(7.11) \\
(0.709)\end{array}$ \\
\hline B1S & $\begin{array}{c}3.00 \\
(7.94) \\
(0.385)\end{array}$ & $\begin{array}{c}6.19 \\
(6.34) \\
(0.302)\end{array}$ & $\begin{array}{c}5.26 \\
(7.35) \\
(0.337)\end{array}$ & $\begin{array}{c}1.28 \\
(5.57) \\
(0.295)\end{array}$ & $\begin{array}{c}0.323 \\
(3.73) \\
(0.238)\end{array}$ & $\begin{array}{c}1.43 \\
(4.60) \\
(0.297)\end{array}$ & $\begin{array}{c}1.30 \\
(3.33) \\
(0.272)\end{array}$ & $\begin{array}{c}1.20 \\
(4.71) \\
(0.433)\end{array}$ & $\begin{array}{c}1.28 \\
(5.14) \\
(0.481)\end{array}$ & $\begin{array}{c}0.253 \\
(6.54) \\
(0.652)\end{array}$ \\
\hline
\end{tabular}

\begin{tabular}{rrrrrrrrrrr}
\hline \multicolumn{2}{c}{ Leedey chondrite***) } & & & & & & & & \\
& 0.378 & 0.976 & 0.716 & 0.230 & 0.0866 & 0.311 & 0.390 & 0.255 & 0.249 & 0.0387 \\
\hline Basalt & 7.80 & 20.5 & 15.6 & 4.34 & 1.36 & 4.81 & 4.78 & 2.77 & 2.66 & 0.388
\end{tabular}

*) These parenthesized values are Leedey-normalized ones $\left(\times 10^{-6}\right)$.

**) These parenthesized values are basalt-normalized ones $\left(\times 10^{-6}\right)$.

***) The data are taken from Leedey chondrite values by Masuda et al. (1973).

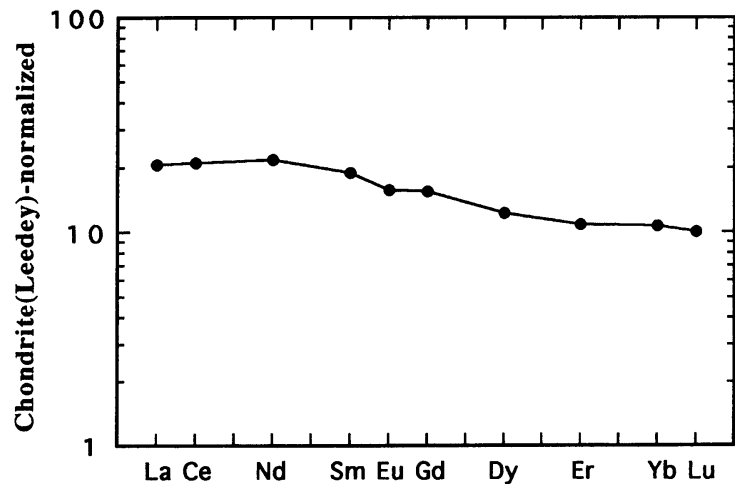

Fig. 1. Leedey chondrite-normalized REE pattern of the basalt from the Mishima lava at the foot of Mt. Fuji.

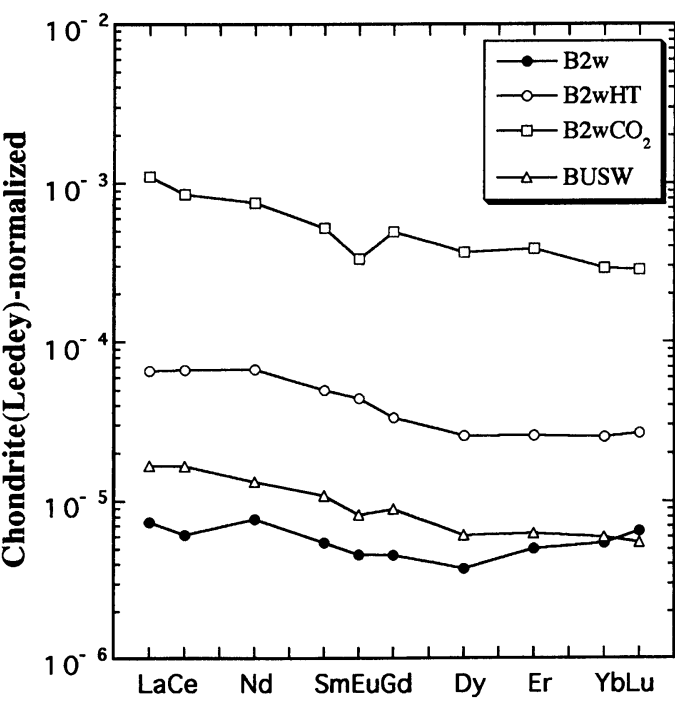

Fig. 2. Leedey chondrite-normalized REE patterns of waters contacted with the basalt. The abbreviations correspond to Table II. 


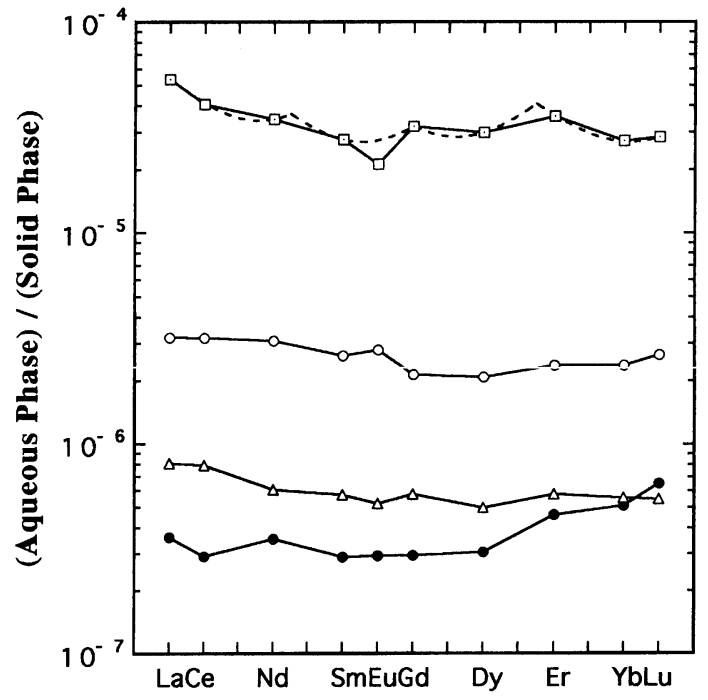

Fig. 3. Basalt-normalized REE patterns of waters contacted with the basalt. Symbols are identical to those in Fig. 2 .

$\mathrm{Ce}, \mathrm{Nd}, \mathrm{Sm}, \mathrm{Eu}$ and $\mathrm{Gd}$, respectively.

The pattern for the basaltic rock is almost flat showing somewhat higher abundances for light REE than those for heavy REE, with slightly negative $\mathrm{Eu}$ anomaly. The pattern for the water (sample B2w) contacted with the basalt at $20^{\circ} \mathrm{C}$ shows clear W-type tetrad effect and negative $\mathrm{Ce}$ and $\mathrm{Eu}$ anomalies. It is noted that $\mathrm{B} 2 \mathrm{w}$ has different pattern from source rock. The pattern of $\mathrm{B} 2 \mathrm{~W}$ is rather similar to that of seawater in shape. ${ }^{1), 8), 9)}$ The REE concentrations in B2w (soaking for 2 weeks) are almost the same as those in B1L (soaking for 1 month), but the difference in the $\mathrm{Eu}$ content is relatively large, which may have something to do with the difference in carrier mineral (feldspar).

On the other hand, sample BUSW placed under supersonic waves for 4 hours have smooth REE pattern, having little tetrad effect and no Ce anomaly, resembling that of the basalt. BUSW contains higher abundances than B2w in spite of short period of 4 hours for interaction between water and the basalt. It is difficult to judge that BUSW (4 hours soaking under ultrasonic agitation) exhibits the tetrad effect. Although there is a slight trend from La through $\mathrm{Lu}$, it would be significant that the mobilization of $\mathrm{L}_{n}{ }^{3+}$ ion into an aqueouis phase appears to take place almost unselectively from the viewpoint of the tetrad phenomenon. This is interpreted to imply that the violent acceleration of transfer of $\mathrm{Ln}^{3+}$ ion into the aqueous phase is not favorable for the appearance of the tetrad phenomenon. Perhaps this is due to the fact that the mechanical abrasion of grain surface is a dominant factor to accelerate the $\mathrm{Ln}^{3+}$ ion mobilization.

The pattern for $\mathrm{B} 2 \mathrm{wHT}$ (soaking at $70^{\circ} \mathrm{C}$ for 2 weeks) is also flat, and absence of Ce anomaly and positive $\mathrm{Eu}$ anomaly may merit attention. There seems to be a weak tetrad effect for the heavy REE span, but one cannot recognize such an effect for the light REE span. It is suspected that the grain surface of rock was subject to the hydrolytic alteration at $70^{\circ} \mathrm{C}$ soaking, with the simultaneous aquation of $\mathrm{Ln}^{3+}$ ion on the grain surface, that, when the aquated $\mathrm{Ln}^{3+}$ ion on the grain surface is mobilized into the aqueous phase, the tetrad effects are diminished thermodynamically in comparison with the case where non-aquated $\mathrm{Ln}^{3+}$ ion in crystalline state is directly mobilized into the aqueous phase. (The tetrad effect can be considered to reflect the difference in physico-chemical condition surrounding the $\mathrm{Ln}^{3+}$ ions between two phases in question.) At the same time, it is also probable that non-selective "simple" dissolution of REE into the aqueous phase has been promoted at $70^{\circ} \mathrm{C}$. Following the former interpretation, the reaction rate of aquation of the rock surface should be quicker at $70^{\circ} \mathrm{C}$ than

Table IV. Degrees of the first (second), third and fourth tetrad effects, and Ce and Eu anomalies in waters contacted with the basalt, including $\mathrm{pH}$ values after interaction

\begin{tabular}{|c|c|c|c|c|c|c|c|c|c|c|c|}
\hline \multirow{2}{*}{ Sample } & \multirow{2}{*}{$\mathrm{pH}$} & \multicolumn{5}{|c|}{ Basalt-normalized } & \multicolumn{5}{|c|}{ Chondrite-normalized } \\
\hline & & $\mathrm{T}(1,2)$ & $\mathrm{T}(3)$ & $\mathrm{T}(4)$ & $\mathrm{Ce}_{\mathrm{N}} / \mathrm{Ce}_{\mathrm{N}}{ }^{*}$ & $\mathrm{Eu}_{\mathrm{N}} / \mathrm{Eu}_{\mathrm{N}} *$ & $\mathrm{~T}(1,2)$ & $\mathrm{T}(3)$ & $\mathrm{T}(4)$ & $\mathrm{Ce}_{\mathrm{N}} / \mathrm{Ce}_{\mathrm{N}}{ }^{*}$ & $\mathrm{Eu}_{\mathrm{N}} / \mathrm{Eu}_{\mathrm{N}} *$ \\
\hline $\mathrm{B} 2 \mathrm{w}$ & 6.7 & 2.5 & 3.7 & 2.7 & 0.82 & 1.0 & 2.6 & 4.9 & 2.3 & 0.82 & 0.92 \\
\hline B2wHT & 7.8 & 0.056 & 1.6 & 1.7 & 1.1 & 1.2 & 0.11 & 1.9 & 0.84 & 1.0 & 1.1 \\
\hline $\mathrm{B} 2 \mathrm{wCO}_{2}$ & 5.3 & 3.2 & 3.0 & 2.5 & 0.88 & 0.71 & 3.3 & 3.3 & 1.7 & 0.88 & 0.65 \\
\hline BUSW & 8.2 & 0.14 & -0.82 & 0.097 & 1.1 & 0.91 & 0.24 & 2.5 & -0.72 & 1.1 & 0.83 \\
\hline $\mathrm{B} 1 \mathrm{~L}$ & 7.2 & 2.8 & 4.5 & 2.7 & 0.70 & 0.74 & 2.8 & 4.8 & 1.9 & 0.74 & 0.68 \\
\hline B1S & 7.2 & 1.5 & 5.2 & 3.6 & 0.66 & 0.80 & 1.5 & 5.3 & 2.8 & 0.82 & 0.74 \\
\hline
\end{tabular}


the mobilization rate of $\mathrm{Ln}^{3+}$ from the rock surface.

The pattern for sample $\mathrm{B}_{2} \mathrm{wCO}_{2}$ with $\mathrm{CO}_{2}$ introduction shows a W-type tetrad effect and negative Ce anomaly, degree of which is slightly smaller than B2w (Table IV). The high concentrations of REE in $\mathrm{B}_{2} \mathrm{wCO}_{2}$, about one hundred times those in $\mathrm{B} 2 \mathrm{w}$, can be understood in terms of gentle stirring of the aqueous phase by $\mathrm{CO}_{2}$ bubbles, lowering of $\mathrm{pH}$ to 5.3 and formation of carbonate complex. That is, a combination of those effects is understood to have promoted in effect the solubility of REE from rock into water. However, it should be noted that, apart from the enhancement of concentration, tetrad effects are clearly recognized and that $\mathrm{T}(1,2) \geq \mathrm{T}(3) \geq \mathrm{T}(4)$. (As for $\mathrm{B} 2 \mathrm{wCO}_{2}$, four parabolic curves are drawn (Fig. 3) in addition to the zig-zag pattern formed by connecting the adjacent points.) Some additional attention might be paid to the fact that there is some difference in fine features of patterns between $\mathrm{B}^{2} \mathrm{wCO}_{2}$ and $\mathrm{B} 2 \mathrm{w}$, in particular, for the heavy REE span. Further, it intrigues us whether a stage of mobilization of $\mathrm{Ln}^{3+}$ ion into the aqueous phase precedes the carbonate complex formation, because this problem is more or less related with the mechanism responsible for the tetrad phenomenon. However, our present informations is too poor to discuss the elementary processes.

In summary, the tetrad phenomenon arises at room temperature under gentle conditions. Strange to say, there is no difference in REE concentration in the aqueous phase between soaking of 2 weeks and 1 month. Slow bubbling of $\mathrm{CO}_{2}$ gas into the aqueous phase enhances the REE concentration by a factor of about 100 , where the tetrad effect is retained distinctly. In the treatment at $70^{\circ} \mathrm{C}$, the tetrad effect is diminished to an almost negligible extent. This might be interpreted to be related with the accelerated formation of aquated $\mathrm{Ln}^{3+}$ ion on the grain surface, prior to mobilization into aqueous solution. Although the ultrasonic agitation of the experimental system as a whole appears to promote the mobilization of $\mathrm{Ln}^{3+}$ ion into the aqueous phase, this processing causes little tetrad effect. This observation suggests strongly that the tetrad effect reflects a reaction of chemical nature. Negative Ce anomaily seems to be accompanied with the tetrad effect.

Acknowledgments. We wish to thank Prof. K. Yamasaki, M. J. A., for his continued interest in our work. Our thanks are extended to Prof. H. Shimizu for his advice on geological problems.

\section{References}

1) Masuda, A., and Ikeuchi, Y. (1979) Geochem. J. 13, $19-22$.

2) Nugent, L. J. (1970) J. Inorg. Nucl. Chem. 32, 339-343.

3) Peppard, D. F., Mason, G. W., and Lewey, S. (1969) J. Inorg. Nucl. Chem. 31, 2271-2272.

4) Peppard, D. F., Bloomquist, C. A. A., Horwitz, E. P., Lewey, S., and Mason, G. W. (1970) J. Inorg. Nucl. Chem. 32, 339-343.

5) Masuda, A., Kawakami, O., Dohmoto, Y., and Takenaka, T. (1987) Geochem. J. 21, 119-124.

6) Masuda, A., Matsuda, N., Minami, M., and Yamamoto, H. (1994) Proc. Japan Acad. 70B, 169-174.

7) Masuda, A., Nakamura, N., and Tanaka, T. (1973) Geochim. Cosmochim. Acta 37, 239-248.

8) Elderfield, H., and Greaves, M. J. (1982) Nature 296, 214-219.

9) De Baar, H. J. W., Bacon, M. P., Brewer, P. G., and Bruland, K. W. (1985) Geochim. Cosmochim. Acta 49, 1943-1959.

10) Tsuya, H. (1935) Bull. Earthq. Res. Inst. 13, 645-659. 